\title{
AVALIAÇÃO PELOS PARES NAS REVISTAS BRASILEIRAS DE CIÊNCIA DA INFORMAÇÃO: procedimentos e percepções dos atores ${ }^{1}$ PEER REVIEW IN BRAZILIAN JOURNALS OF INFORMATION SCIENCE: procedures and perceptions of actors
}

Cleusa Pavan Mestre em Comunicação e Informação Bibliotecária - Instituto de Física/UFRGS Membro do Grupo de Pesquisa em Comunicação Científica do PPGCOM/UFRGS cleusa.pavan@ufrgs.br

Ida Regina Chitto Stumpf Doutora em Ciências da Comunicação Professora do PPGCOM/UFRGS Coordenadora do Grupo de Pesquisa em Comunicação Científica do PPGCOM/UFRGS irstumpf@ufrgs.br

\begin{abstract}
Resumo
O estudo analisa o processo de avaliação pelos pares empregado pelas revistas brasileiras de Ciência da Informação com conceito A (nacional), conforme o Qualis/CAPES 2006, num total de seis revistas. Os sujeitos do estudo foram os editores, membros das comissões editoriais, avaliadores e autores. A coleta de dados foi realizada através de questionários específicos para cada categoria de sujeitos e por meio da análise dos fascículos publicados em 2006. Apresenta os principais procedimentos de avaliação adotados pelas revistas estudadas. Conclui que as revistas, em sua maioria, seguem procedimentos similares e de acordo com os padrões científicos.
\end{abstract}

Palavras-chave: Avaliação pelos pares. Revistas científicas. Ciência da Informação.

\section{INTRODUÇÃO}

A avaliação pelos pares (peer review ou referee system, em inglês) pode ser considerada um filtro para os manuscritos submetidos à publicação em revistas científicas. Para isso é necessária uma apreciação minuciosa dos originais por especialistas para indicar a sua aceitação, reformulação ou

\section{cc) (†)} DOI 10.5007/1518-2924.2009v14n28p73

\footnotetext{
${ }^{1}$ Versão preliminar apresentada no IX Encontro Nacional de Pesquisa em Ciência da Informação (ENANCIB), na cidade de São Paulo, em 2008. 
recusa. Esses especialistas são os pares daqueles que estão em julgamento e considerados capazes de fornecer opinião confiável, pela sua formação e experiência (DAVYT GARCÍA; VELHO, 2000).

Entre as funções da avaliação pelos pares para a ciência e para as práticas de comunicação científica, Kronick (1990) destaca a manutenção da literatura especializada no mais alto nível de qualidade. Gérvas e Pérez Fernández (2001) acrescentam outros papéis para o processo de avaliação de originais, como: selecionar os trabalhos, elegendo os mais inovadores e realizados com o máximo de rigor científico; melhorar a apresentação dos artigos quanto à clareza, lingüística, lógica interna, referências e outros aspectos; diminuir a chance de publicar trabalhos fraudulentos ou publicados anteriormente; e gerar um ambiente de qualidade, neutralidade e credibilidade científica. Assim, a qualificação que a avaliação pelos pares pode acrescentar à literatura científica e especialmente às revistas científicas é enfatizada tanto pelos autores citados quanto por todos os que se preocupam com a divulgação do conhecimento e a evolução da ciência.

$\mathrm{O}$ surgimento da avaliação pelo pares deve-se às primeiras sociedades e academias científicas, do século XVI e XVII, e suas revistas. A preocupação com os trabalhos que poderiam ser publicados nasceu, então, entre cientistas reunidos em grupos organizados e dispostos a executar a avaliação de originais. Hames (2007) explica que somente na metade do século XX o processo de peer review foi bastante difundido e razoavelmente padronizado, sendo que dois fatores levaram à sua disseminação: o aumento de submissões às revistas, que fizeram os editores se tornar mais seletivos, e o aumento da especialização das áreas, que fizeram os editores buscar a opinião de outros pesquisadores pela impossibilidade de dominar todos os temas.

As revistas científicas podem variar nos procedimentos de avaliação adotados (número de avaliadores por artigo, critérios de seleção de artigos, formulação e entrega dos pareceres para autores, prazos de avaliação, entre outros) e, também, no tipo de avaliação: fechada ou cega (single blind peer review), fechada ou cega em dobro (double blind peer review) ou aberta (open peer review). Essas variações estão relacionadas às formas de disseminar os resultados de pesquisa, de acordo com as diferentes áreas de conhecimento, bem como aos desejos e interesses dos cientistas que as integram.

Os atores essenciais do processo de avaliação são os editores, os membros de comissão editorial, os avaliadores e os autores. Os editores são os principais responsáveis pela revisão dos originais, além de terem outras funções relacionadas à produção de uma revista. Conforme Meadows (1999), os editores são aqueles que realizam, em primeira instância, o controle do conteúdo dos trabalhos 
científicos. Os membros de comissão editorial costumam assessorar o editor na tomada de decisões sobre a publicação e ajudam na seleção dos avaliadores (STUMPF, 2005).

Os avaliadores também chamados consultores ou pareceristas devem fornecer ao editor um parecer conclusivo sobre os trabalhos analisados que indique a sua recusa, aceite total ou aceite parcial (necessidade de correções). Meadows (1999) aponta que a grande parte dos artigos publicados sofre modificações que vão de alterações insignificantes até as de grande vulto. Esses avaliadores podem ser membros do conselho consultivo da revista ou contribuir de forma esporádica quando requisitados pelo editor (conhecidos como avaliadores ad hoc ou externos).

Por fim, os autores são os responsáveis intelectuais dos artigos e sempre devem observar as normas de apresentação de originais ou instruções aos autores para diminuir suas chances de reprovação. Eles podem ter um papel ativo no processo de revisão, como contatar o editor para perguntar sobre o andamento do seu manuscrito, para questionar os comentários dos avaliadores ou para pedir a reconsideração de uma rejeição, entre outros (WELLER, 1995). Ou podem exercer um papel passivo, aceitando os resultados da avaliação sem questionar.

$\mathrm{Na}$ maior parte das revistas científicas, os editores, os membros de comissão editorial e os avaliadores não são remunerados, porém adquirem certas vantagens (status, reconhecimento dos colegas, experiência editorial e outras) ao dedicar parte de seu tempo para a produção de periódicos. O processo de avaliação pelos pares não é perfeito e a literatura aponta algumas fragilidades, como: lentidão, dificuldade dos avaliadores de detectar fraudes e erros estatísticos, rejeição de novas idéias, possibilidade de plágio, dupla submissão de originais, subjetividade, conservadorismo, favorecimento às redes elitistas em detrimento de grupos minoritários (étnicos, mulheres, pesquisadores jovens, pesquisadores de instituições de menor prestígio), conforme apontado por autores como Weller (1995), Davyt García e Velho (2000) e Campanario (2002). O aperfeiçoamento do processo deve ser buscado pelas comunidades científicas.

Embora apresente problemas, a avaliação pelos pares vem sendo utilizada pela maioria dos periódicos, seja na sua forma tradicional ou não. O emprego das tecnologias de informação e comunicação para a produção das revistas, principalmente a Internet, trouxeram inovações para o julgamento dos artigos, como por exemplo, a possibilidade dos leitores serem incluídos no processo ao permitir que comentem os artigos antes ou depois de serem publicados no site da revista. Costa (2000) indica que o uso da tecnologia na revisão de originais potencializou a comunicação entre os atores e reduziu o tempo gasto com impressão, reprodução, serviços postais, entre outros. Ainda que não seja totalmente consensual, a maioria dos pesquisadores ainda acha que a avaliação pelos pares 
é o melhor meio para a seleção de artigos para publicação e desejam vida longa a esse processo até que seja encontrado algo melhor (WILLIAMSON, 2003).

No Brasil, poucos estudos sobre avaliação pelos pares foram realizados. Destacam-se, entre eles: Castro, Negrão e Zaher (1996) que verificaram os procedimentos editoriais empregados pelos editores de revistas da área da saúde da América Latina e do Caribe, indexadas no LILACS e MEDLINE; Mueller (1997) estudou as práticas de avaliação de artigos em revistas de diferentes áreas e financiadas pelo Conselho Nacional de Desenvolvimento Científico e Tecnológico (CNPq) e pela Financiadora de Estudos e Projetos (FINEP); Davyt García (2001) investigou a sistemática da revisão por pares e da tomada de decisão quanto à alocação de recursos para pesquisa no CNPq e na Fundação de Amparo à Pesquisa do Estado de São Paulo (FAPESP) e, por fim, Stumpf (2008) analisou a avaliação de originais nas revistas brasileiras de Comunicação. Nenhum deles, porém, investigou a avaliação de originais realizada por periódicos científicos em Ciência da Informação. Em vista disso, desenvolveu-se este estudo com o objetivo principal de analisar o processo de avaliação pelos pares empregado pelas revistas brasileiras de Ciência da Informação, a partir da percepção dos editores, membros das comissões editoriais, avaliadores e autores, para assim compreender as formas de construção e comunicação do conhecimento científico desse campo.

\section{PROCEDIMENTOS METODOLÓGICOS}

Para esta pesquisa, de natureza descritiva e de abordagem quali-quantitativa, selecionou-se as revistas brasileiras de Ciência da Informação com conceito A (nacional), conforme Qualis 2006 da Coordenação de Aperfeiçoamento de Pessoal de Nível Superior (CAPES). Tal seleção totalizou seis periódicos, a saber: Ciência da Informação, do Instituto Brasileiro de Informação em Ciência e Tecnologia (IBICT); DataGramaZero: revista de Ciência da Informação, do Instituto de Adaptação e Inserção na Sociedade da Informação (IASI); Encontros Bibli: revista eletrônica de Biblioteconomia e Ciência da Informação, da Universidade Federal de Santa Catarina (UFSC); Informação \& Sociedade: estudos, da Universidade Federal da Paraíba (UFPB); Perspectivas em Ciência da Informação, da Universidade Federal de Minas Gerais (UFMG) e Transinformação, da Pontifícia Universidade Católica de Campinas (PUC-Campinas). Foram utilizados os fascículos publicados em 2006, mas excluiu-se da análise os números temáticos ou especiais das revistas 
Ciência da Informação (v. 35, n. 2 - Acesso Livre à Informação) e Encontros Bibli (Primeiro Número especial $-1^{\circ}$ semestre e Segundo Número Especial $-2^{\circ}$ semestre).

Com base nesse corpus, foram definidos os sujeitos do estudo, nesta ordem: editores científicos (excluíram-se os editores adjuntos, associados ou convidados); membros das comissões editoriais; avaliadores (membros do conselho consultivo e/ou ad hoc) e autores (somente da seção de artigos). Como um mesmo sujeito pode desempenhar duas ou mais funções concomitantemente nas revistas (por exemplo, editor e autor, avaliador e membro de comissão editorial), eliminou-se os nomes que já constavam na lista anterior para que um mesmo sujeito não recebesse dois instrumentos para responder. O total de sujeitos convidados a colaborar foi de 373 e a distribuição por categoria pode ser verificada na Tabela - Percentual de Questionários Devolvidos, a seguir.

O instrumento de coleta de dados escolhido foi do tipo questionário devido à dispersão dos sujeitos em vários Estados do Brasil e em países estrangeiros. Para cada categoria de sujeitos da pesquisa foram elaboradas perguntas diferenciadas, resultando em quatro questionários. Destaca-se que para cada instrumento foram mantidas as denominações atribuídas pelas próprias revistas no que se refere a sua estrutura editorial (por exemplo, comissão ou comitê editorial), para não gerar confusão quanto ao significado dos termos. Os questionários foram pré-testados antes de sua utilização para verificar a sua validade. O pré-teste foi realizado com dois representantes de cada categoria de sujeitos da revista InTexto, semelhante às revistas do estudo quanto ao conceito Qualis.

A coleta de dados ocorreu em três etapas. Na primeira foram reunidas fotocópias de partes textuais dos fascículos de 2006 que indicavam: a equipe editorial, a lista de avaliadores de cada número, as normas para submissão de trabalhos científicos, as políticas editoriais e as seções específicas sobre a avaliação pelos pares. Salienta-se que as informações disponíveis somente no site das revistas foram coletadas no mês de março de 2007. Considera-se necessário indicar a data da coleta de dados, porque os procedimentos e nomes dos participantes das revistas mudam constantemente. Na segunda etapa elaborou-se uma lista com os nomes dos sujeitos, sua filiação institucional e seu endereço do correio eletrônico (total de 385 sujeitos). Esses dados foram retirados das próprias revistas e quando a filiação e os endereços eletrônicos não eram indicados, foram utilizadas outras fontes para complementar os dados, como a Plataforma Lattes, mantida pelo Conselho Nacional de Desenvolvimento Científico e Tecnológico (CNPq), e/ou o mecanismo de busca Google. Por fim, na terceira etapa foram enviados os questionários para os sujeitos, através do correio eletrônico. Um novo encaminhamento foi necessário para aqueles que não devolveram as respostas dentro do prazo esperado (20 dias). 
O percentual de questionários devolvidos pode ser observado através da Tabela abaixo (o número total de instrumentos enviados difere do total de sujeitos da lista elaborada, pois não foi possível enviá-los para 12 pessoas). Considerou-se suficiente a taxa de retorno de questionários próxima a $50 \%$ para cumprir os objetivos da pesquisa.

Tabela - Percentual de Questionários Devolvidos

\begin{tabular}{lccc}
\hline \multicolumn{1}{c}{ Sujeitos } & Enviados & \multicolumn{2}{c}{ Devolvidos } \\
\hline & $\mathrm{N}^{\circ}$ & $\mathrm{N}^{\circ}$ & $\%$ \\
\hline Editores & 6 & 6 & 100 \\
Membros das comissões editoriais & 29 & 13 & 44,8 \\
Avaliadores & 169 & 97 & 57,4 \\
Autores & 169 & 69 & 40,8 \\
\hline Total & $\mathbf{3 7 3}$ & $\mathbf{1 8 5}$ & $\mathbf{4 9 , 6}$ \\
\hline \multicolumn{2}{c}{ Fonte: Dados da pesquisa. } & &
\end{tabular}

Quanto à análise e descrição dos dados, inicialmente foram lidas as partes textuais específicas das revistas para a descrição de sua estrutura editorial e verificação de alguns procedimentos de avaliação. Em seguida foram apreciadas as respostas aos questionários e tratadas através de percentuais. $\mathrm{Na}$ forma deste artigo deixa-se de apresentar tabelas e gráficos que constam do relatório da pesquisa. As questões abertas foram analisadas com o auxílio do software NVivo 7. As transcrições das respostas dos sujeitos são apresentadas com a seguinte convenção: editores (Ed), membros das comissões editoriais (Co), avaliadores (Av) e autores ( $\mathrm{Au}$ ).

A pesquisa encontrou algumas dificuldades no decorrer da coleta de dados, sendo a primeira a não obtenção de respostas dos sujeitos pertencentes à comissão editorial de uma revista. A segunda refere-se a que um editor considerou algumas questões "Informação privilegiada e não disponível para divulgação". Compreende-se que os editores não desejem tornar públicas determinadas informações, mas ao mesmo tempo fica a impressão de que algo importante do processo está sendo ocultado. Além disso, causam entraves na realização de pesquisas mais completas prejudicando, dessa forma, a própria comunidade científica na qual estão inseridos.

\section{O PROCESSO de AVALIAÇÃo PELOS PARES E ALGUMAS PERCEPÇÕES}


Para esta apresentação, dividiu-se as respostas dos sujeitos em itens: tipo de avaliação e os procedimentos de avaliação, incluindo os prazos, os critérios, a comunicação, os conflitos e a continuidade do processo.

Nas seis revistas estudadas, os procedimentos e os critérios de avaliação foram estabelecidos de forma coletiva pelos editores e seus colaboradores, geralmente os membros das comissões editoriais. Em relação à atualização destes itens, um editor não se manifestou, enquanto os outros indicaram que são feitas atualizações "periódicas", "quando necessárias" ou "constantemente", de acordo com suas palavras. Ressalta-se que outro editor informou: "É feito o acompanhamento de sua eficácia!” (Ed3). Estas constatações e estas expressões demonstram preocupação e controle dos procedimentos e critérios empregados.

Em relação ao tipo de avaliação utilizado, a análise das partes textuais específicas das revistas mostrou que apenas duas delas informam a adoção do sigilo de avaliador e autor (double blind peer review) nas normas para submissão de trabalhos. Três revistas indicaram que não há identificação da autoria, porém não mencionam se o avaliador permanece anônimo. Por fim, outra publicação não especificou o tipo de avaliação. Ressalta-se que os esclarecimentos sobre o tipo de avaliação são importantes para a confiabilidade da revista.

Todos os editores informaram os critérios utilizados para a revisão de artigos e cada revista possui suas particularidades. De modo geral, os critérios abarcam os aspectos formais (aplicação das normas para submissão, correção gramatical, coerência de linguagem, correção de citações e referências, entre outros) e de conteúdo (originalidade, contribuição para a Ciência da Informação, atualidade, revisão bibliográfica e metodologia adequadas, pertinência com os objetivos da revista e outros). Percebe-se que todos os periódicos apresentaram critérios de avaliação estabelecidos e reconhecidos pelas comunidades científicas, entre os quais encontram-se aqueles indicados como básicos por Meadows (1999): originalidade, correção e importância da pesquisa para a área.

A análise dos fascículos mostrou que todas as seis revistas indicam os aspectos formais que os autores devem observar para submeter seus artigos. Quanto aos critérios de conteúdo, todas apontam que os trabalhos devem ser inéditos e estar relacionados com a Ciência da Informação ou ciências correlatas, entretanto somente duas revistas listaram claramente outros critérios de conteúdo além desses, como por exemplo: temas e enfoques inovadores, conceitos atualizados e bem articulados, entre outros. 
Os procedimentos e critérios de avaliação de artigos empregados pelas revistas foram considerados satisfatórios por nove membros das comissões editoriais, porém dois deles fizeram ressalvas e estão destacadas a seguir:

\footnotetext{
Quanto aos itens de conteúdo (relativos à temática) não são oferecidas orientações unívocas sobre o "que" avaliar especificamente (originalidade, atualidade, por exemplo). Porém, não diria que é insatisfatório, uma vez que o corpo editorial é (ou deveria ser) composto por especialistas (estes sim) com conhecimento "satisfatório" quanto às exigências de qualidade para um material que advoga ser "científico", apontando detalhadamente os pontos falhos/de melhoria. Neste sentido, tal subjetividade extrapola qualquer lista de itens/critérios. (Co1).

Como todo procedimento genérico, os da revista em questão se mostram às vezes limitados como roteiro [para] casos de exceção, mas, ao mesmo tempo, a revista oferece plena liberdade (aos avaliadores) de, nestas circunstâncias, afastar-se do roteiro comum e criar uma avaliação especial. (Co2).
}

Percebe-se que as diretrizes de avaliação podem apresentar deficiências quanto a algum item, mas os respondentes lembraram que o avaliador pode extrapolar ou expandir os critérios utilizados por deter, teoricamente, conhecimento para tal ação. Três membros não esclareceram em suas respostas a questão da satisfação e outro respondente apontou a impossibilidade de alcançar um nível satisfatório quanto aos procedimentos e critérios em revistas das Ciências Humanas, Sociais e Sociais Aplicadas, devido à subjetividade e à falta de unanimidade quanto às questões das áreas.

Da mesma forma que a comissão editorial, 81 avaliadores $(83,5 \%)$ consideraram satisfatórios os procedimentos e critérios de avaliação, tendo alguns utilizado adjetivos como "adequados", "bons", "flexíveis", “objetivos", "pertinentes”, “conforme padrão” ou “conforme outras revistas". Dez avaliadores $(10,3 \%)$ demonstraram-se descontentes e fizeram emendas, principalmente, quanto aos critérios utilizados, salientando a necessidade de serem mais "claros", "detalhados", "padronizados" e "incluir escala de avaliação". Vale notar que esses dez consultores referiram-se a três revistas, ou seja, a metade da amostra. Seis $(6,2 \%)$ não responderam a essa questão. Apesar de algumas reservas, percebe-se que a maioria dos membros das comissões editoriais e dos avaliadores apresentou-se satisfeita com os procedimentos adotados e critérios utilizados pelas revistas para as quais colaboram.

Entre os autores, $57(82,6 \%)$ apontaram que os procedimentos e os critérios de avaliação foram expressos pelas revistas de forma clara. Alguns os qualificaram como "satisfatórios", "adequados", "coerentes", “conforme padrão", “objetivos", "pertinentes", "bons" ou "muito bons". Os demais autores $(17,4 \%)$ manifestaram descontentamento total ou parcial quanto à clareza dos procedimentos ou critérios. Alguns destacaram que os periódicos deveriam ser mais explícitos e Enc. Bibli: R. Eletr. Bibliotecon. Ci. Inf., ISSN 1518-2924, Florianópolis, v. 14, n. 28, p. 73-92, 2009. 
específicos quanto aos critérios de avaliação e ao número de avaliadores por artigo. Uma única revista recebeu cinco dos 12 comentários descontentes, outra recebeu três, uma recebeu dois e duas revistas receberam um comentário cada. Embora em torno de $80 \%$ dos autores aprovem os procedimentos de avaliação e os considerem divulgados com clareza pelas revistas, é preciso levar em conta que uma minoria apontou insatisfação. Tornar o tratamento dado para os artigos mais visível aos olhos dos autores, desde a submissão até a recusa ou publicação, pode evitar dúvidas e obstáculos durante o processo de peer review.

A seleção dos avaliadores é feita através de critérios estabelecidos pelas próprias revistas. Quando questionados sobre esse tema, um editor considerou: "Informação privilegiada e não disponível para divulgação." (Ed1). O conhecimento de um ou vários assuntos dentro da área de Ciência da Informação é o critério mais comum entre as outras revistas, conforme informado por cinco editores. Em seguida, foram assinalados os critérios senioridade acadêmica e titulação por quatro editores, envolvimento em atividades de pesquisa por três e a produção científica por dois.

Nenhum editor indicou outros critérios além dos sugeridos na pergunta, porém em outro ponto do questionário um deles expressou que a instituição responsável pela publicação da revista, através de um comitê específico, determinou que somente poderiam participar como avaliadores aqueles “[...] especialistas com a titulação 'PhD', com mais de 2 anos e, em casos especiais, profissionais considerados com notório saber." (Ed6). Pode-se perceber que os periódicos utilizam alguns critérios comuns para compor o seu grupo de avaliadores que corresponde aos aceitos pela comunidade científica.

O número de avaliadores por artigo também não é igual nas seis revistas estudadas: três delas submetem cada original a dois avaliadores (sendo designado um terceiro quando há divergência de opinião) e outras três utilizam três avaliadores. A pesquisa da Association of Learned and Professional Society Publishers (ALPSP) e da European Association of Science Editors (EASE) (2000), sobre a peer review em periódicos de várias disciplinas, verificou que $73 \%$ dos respondentes usavam dois avaliadores por artigo, 18\% usavam três, $6 \%$ utilizavam apenas um e outros 3\% empregavam mais de três. Stumpf (2005) destaca que o mais comum é adotar dois avaliadores e, quando há discordância entre os pareceres, um terceiro pode ser requisitado. Portanto, ao comparar com a literatura, constata-se que as revistas de Ciência da Informação analisadas seguem o padrão da maioria dos periódicos científicos.

Os avaliadores que contribuem com a revisão de originais são recompensados de formas variadas. De acordo as respostas dos editores, três revistas publicam os nomes dos avaliadores nos fascículos 
(uma delas também emite uma declaração de participação e outra encaminha um exemplar mais um documento comprobatório). Para um periódico, o editor informou enviar os exemplares publicados e uma declaração de pertencimento do grupo de avaliadores. Outro editor considerou: "Informação privilegiada e não disponível para divulgação." (Ed1). Ressalta-se que, em uma revista os avaliadores eram recompensados com um exemplar quando a mesma era impressa, porém o editor não indicou a existência de outras formas de recompensa. Nenhum indicou pagamento de honorários. Tradicionalmente os consultores não são recompensados, aponta Hames (2007) em recente livro publicado sobre o assunto. Em oposição a isso, a maioria das revistas estudadas reconhece o trabalho dos avaliadores, demonstrando apreço pela tarefa desempenhada. $\mathrm{O}$ mesmo pode ser verificado na investigação da ALPSP/EASE (2000), que apresentou o reconhecimento dos avaliadores na revista como a prática assinalada por mais de $40 \%$ dos respondentes.

Quando questionados sobre o tempo médio que um artigo leva para ser avaliado (desde a submissão pelo autor até a decisão final pela sua publicação/recusa), quatro editores indicaram um período de até quatro meses e outro informou um período que pode levar mais de quatro meses, não especificando o tempo. Um editor não assinalou nenhuma das opções da questão. Castro, Negrão e Zaher (1996) encontraram em periódicos da área da saúde tempo médio semelhante ao das revistas de Ciência da Informação. O tempo entre a avaliação inicial do trabalho, a avaliação pelos consultores e a aprovação ou rejeição verificado pelas pesquisadoras foi em torno de quatro meses. A pré-avaliação dos artigos antes da remessa para os pareceristas é realizada por quatro revistas. Um editor apontou que não segue esse procedimento e outro não respondeu à questão. Quando a pré-avaliação ocorre, o responsável é o editor em duas revistas, ou o editor e o coordenador editorial em outra e o grupo de editores na quarta revista. A pré-avaliação é uma prática que também foi observada por Stumpf (2008) nos periódicos de Comunicação: todos os editores indicaram realizar uma primeira revisão.

Os avaliadores são sempre contatados previamente para verificar a sua disponibilidade de tempo, de acordo com a resposta dos seis editores. A adoção dessa prática auxilia a execução da avaliação pelos pares e colabora para diminuir o tempo entre a submissão e avaliação dos artigos, pois com isto os editores evitam a remessa de textos a consultores impossibilitados, além do periódico se mostrar atencioso com seus colaboradores.

O tempo estipulado pelas revistas para os avaliadores entregarem seus pareceres varia entre 15 dias a um mês. Aqui, verifica-se uma similaridade com as revistas de Comunicação, cujo prazo mais 
comum dado aos pareceristas é de um mês (STUMPF, 2008) e com a pesquisa da ALPSP/EASE (2000) que oferece o período de três a quatro semanas.

Os avaliadores também confirmaram que, em geral, o tempo oferecido pelas revistas varia entre duas semanas $(36,1 \%)$ a um mês $(40,2 \%)$, mas que, quando solicitado, às vezes o prazo pode ser ampliado. Percebe-se que as respostas dos editores e avaliadores estão em consonância, embora alguns poucos avaliadores tenham apontado outros prazos para a entrega dos pareceres ou a ausência dos mesmos. Esse aspecto pode estar relacionado, possivelmente, à falta de lembrança de dados mais específicos quando do preenchimento do formulário.

O cumprimento do prazo estipulado pelos editores não é uma constante entre as revistas. Apenas um editor afirmou que o prazo é sempre cumprido pelos avaliadores, enquanto quatro indicaram que somente às vezes isto ocorre. Outro respondeu: "Informação privilegiada e não disponível para divulgação." (Ed1). Para aquelas revistas em que o prazo não é sempre cumprido, os editores declararam que são feitas cobranças cordiais para o envio dos pareceres e, em alguns casos, os prazos podem ser renegociados. Um dos editores destacou que: "Para evitar e/ou tentar sanar essa barreira adotamos a prática de comunicar quando o prazo se aproxima e quando expira, desta vez cobrando e dando um prazo urgente para o envio do parecer.” (Ed4). A não observância dos prazos de entrega pode atrasar a publicação de um artigo específico ou prejudicar a periodicidade regular dos fascículos.

No estudo de Mueller (1997) é possível verificar que a maioria dos editores indicou que alguns avaliadores demoram a enviar suas avaliações, ocorrendo um equilíbrio entre aqueles que assinalaram, as alternativas: "não há demora significativa" e "alguns avaliadores nunca respondem”. Assim, parece difícil a obtenção de pareceres em sua totalidade dentro do prazo demarcado em qualquer área do conhecimento.

Ainda sobre o prazo para entrega dos pareceres, 88 avaliadores $(90,7 \%)$ que participaram desta pesquisa afirmaram cumpri-lo. A seguir, dois comentários sobre o tema: "Costumo cumprir os prazos, pois reconheço que um atraso no processo de revisão por pares tem reflexos significativos no fluxo da comunicação científica." (Av35) e "Costumo cumprir os prazos; quando avalio a impossibilidade de dar conta dos mesmos, declino do convite.” (Av91). Outros sete avaliadores $(7,2 \%)$ afirmaram que, geralmente, não conseguem atender ao tempo limite devido à quantidade de trabalho ou ao texto a ser avaliado. Apenas dois avaliadores (2,1\%) não responderam à questão.

Quanto à suficiência do prazo para proceder à análise, 30 avaliadores (30,9\%) não comentaram sobre esse tema e dois $(2,1 \%)$ não responderam às perguntas da questão, como informado no 
parágrafo anterior. Assim, dos 65 (67\%) que responderam, 44 avaliadores consideraram o prazo suficiente, 16 insuficiente e para cinco o prazo é relativo, porque pode estar sujeito ao período do ano em que é solicitado e da sua agenda de trabalho, ou seja, depende do tempo disponível. Aqueles que declararam ser insuficiente o período, referiram-se a três das seis revistas analisadas.

O número aproximado de artigos analisados pelos avaliadores, tomando como incidente crítico o ano de 2006, variou de um a 11. A média de artigos por revisor foi de 2,7 (para os respondentes que informaram um intervalo aproximado de artigos analisados, optou-se por contar o maior número). Foram excluídos da análise da questão seis avaliadores, pois as respostas estavam incompletas (alguns justificaram a falta de lembrança dos dados). Glogoff (1988) descobriu resultado parecido com revistas de Biblioteconomia, em que a maior parte dos avaliadores havia revisado de um a três manuscritos no período de um ano.

Os pareceristas também foram indagados sobre as horas, em média, usadas para a apreciação de um artigo. A maior parte (41 ou 42,3\%) informou utilizar mais de três horas. Outros 27 avaliadores $(27,8 \%)$ utilizam de duas a três horas, $23(23,7 \%)$ de uma a duas horas, cinco até uma hora $(5,2 \%)$ e um (1\%) não respondeu. Nos estudos de Yankauer (1990) e de McNutt et al. (1990), com revistas de Medicina, em que o tempo médio usado pelos avaliadores foi de 2,7 e 3 horas, respectivamente, percebe-se uma similaridade com os resultados encontrados nesta pesquisa.

Quanto às instruções para os avaliadores, cinco editores afirmaram oferecê-las. Na maioria das revistas essas instruções são encaminhadas para os pareceristas juntamente com o artigo, através do formulário de avaliação. Um dos editores destacou que as recomendações ficam disponíveis no Sistema Eletrônico de Editoração de Revistas (SEER) para consulta pelos avaliadores. Para outro editor essa é: "Informação privilegiada e não disponível para divulgação." (Ed1). Meadows (1999) aponta que o oferecimento de instruções sobre os pontos a serem examinados é um procedimento adotado pela grande parte dos periódicos científicos. Isso demonstra que as revistas estudadas estão de acordo com a prática comumente utilizada pela ciência. Nas revistas brasileiras de Comunicação não ocorre o mesmo. $\mathrm{O}$ envio de formulário de avaliação é um procedimento adotado por poucos títulos (STUMPF, 2008).

O recebimento de algum tipo de instrução foi confirmado por 74 avaliadores (76,3\%), enquanto 16 (16,5\%) apontaram não ter obtido. Esses últimos referiram-se a cinco das seis revistas analisadas, sendo que alguns acrescentaram comentários: um indicou que somente foi informada a data esperada para a devolução do parecer; outros três indicaram ter recebido apenas o formulário de 
revisão e um precisou utilizar sua experiência como avaliador. Outros sete avaliadores (7,2\%) não responderam à questão.

O formato do parecer solicitado aos avaliadores variou entre os periódicos estudados. Conforme dois editores, é solicitada uma combinação de formulário/checklist mais um parecer descritivo, enquanto para outros dois é necessário um parecer descritivo. Um editor informou o uso de um formulário para inserir comentários gerais e sugestões. Por fim, outro considerou: "Informação privilegiada e não disponível para divulgação.” (Ed1).

Com relação à comunicação entre a revista e os autores, todos os editores afirmaram comunicar-se com os autores sobre o andamento do processo de avaliação, desde o recebimento dos artigos até seu aceite ou recusa, com exceção de um editor que também afirmou ser uma: "Informação privilegiada e não disponível para divulgação.” (Ed1). O contato, lembraram alguns editores, pode ser realizado pelo correio eletrônico ou pelo próprio SEER (para aqueles periódicos que utilizam o sistema). Stumpf (2008) verificou que essa é uma prática comum também entre as revistas de Comunicação.

Entre os autores não se verifica a mesma unanimidade no que se refere à questão comunicacional. Foram $48(69,6 \%)$ que informaram ter ocorrido contato, enquanto nove (13\%) apontaram que não e referiram-se a cinco revistas estudadas. Oito autores $(11,6 \%)$ lembraram o software utilizado pelos periódicos e outros quatro (5,8\%) informaram que o contato dos editores ocorrera com os coautores do seu artigo. Embora a minoria tenha acusado a ausência de contato, estes comentários podem significar que as revistas precisem adotar mais cuidados nessa etapa no decorrer da avaliação.

Entre os 48 autores que indicaram a ocorrência da comunicação, 28 consideraram satisfatória, seis de forma não satisfatória, dois parcialmente satisfatória e o restante não opinou. Para os oito autores que lembraram o software, em que é possível acompanhar o processo editorial, somente um mostrou-se satisfeito e os outros não se manifestaram acerca da questão. Ressalta-se que somente uma revista não recebeu comentários de autores insatisfeitos ou que o editor não teria comunicado sobre o andamento do processo. Também observou-se opiniões distintas entre os autores de uma mesma revista quanto à comunicação realizada.

Os pareceres elaborados pelos avaliadores são entregues aos autores por cinco dos seis editores, sendo que o seu formato é diferenciado entre as revistas: duas enviam um parecer elaborado pelos editores com base na opinião dos avaliadores e outras duas encaminham os pareceres dos avaliadores tal como são apresentados. Por fim, um editor não se manifestou sobre o formato do 
parecer, mas apontou que os questionamentos dos autores sempre são respondidos, e outro editor indicou: "Informação privilegiada e não disponível para divulgação." (Ed1).

Entre os avaliadores, verificou-se que 68 (70,1\%) deles autorizam o encaminhamento do seu parecer para os autores. De forma geral, eles responderam que é uma ação necessária para possibilitar o aperfeiçoamento do artigo ou porque é uma etapa do processo de publicação e construção da ciência. As transcrições a seguir demonstram isso: "Entendo a avaliação pelos pares como parte do processo de comunicação científica, onde o autor submete o seu trabalho à apreciação dos colegas. Por isso, considero fundamental o repasse dos pareceres aos autores." (Av36) e "Sim, porque é uma devolução importante para os autores, permite-lhes corrigir, reorientar ou repensar algumas das afirmações ou metodologias que utilizam.” (Av61).

Ainda, desses 68 avaliadores que costumam autorizar a entrega dos pareceres, dois fizeram comentários específicos. O primeiro indicou: “Apenas para autores cujos artigos percebo que são derivados de dissertações e teses, pois entendo que o parecer ensina aos jovens pesquisadores como escrever um bom artigo que divulgue sua pesquisa." (Av72), e o segundo respondeu: "Quando necessário, principalmente quando o artigo é voltado a assuntos fora de nossa área de atuação." (Av87).

Entre o restante dos avaliadores, 19 (19,6\%) informaram que não haviam sido questionados a respeito pelas revistas, porém autorizariam o repasse; sete $(7,2 \%)$ não costumam autorizar e dois $(2,1 \%)$ não preencheram a questão. Destaca-se um respondente que indicou: "Não há essa opção no nível em que atuo na [revista X].” (Av42). Alguns avaliadores que não autorizam o encaminhamento do parecer, explicaram que não o fazem por questões éticas, para a preservação da sua identidade ou para não influenciar o autor. Pelas respostas obtidas em relação aos pareceres, fica evidenciado, de um modo geral, o intuito de colaboração dos avaliadores com os artigos revisados e a compreensão de seu papel dentro do processo de julgamento.

O recebimento dos pareceres foi acusado por 63 autores (91,3\%). Desse total, 38 consideraram, conforme suas palavras, "esclarecedor, "enriquecedor", "satisfatório", "construtivo" ou "pertinente"; 19 não indicaram se o parecer foi claro e seis avaliaram que não era satisfatório ou deixava dúvidas. Apenas quatro autores $(5,8 \%)$ indicaram não ter recebido o parecer e dois autores $(2,9 \%)$ não responderam à questão. Esses resultados confirmam a resposta da maioria dos editores que apontou entregar os pareceres para os autores. Tal procedimento deve ser exaltado, pois é a única forma dos autores aperfeiçoarem seus originais. 
A decisão final sobre a publicação dos artigos é tomada de forma diferenciada. Para três revistas os editores são os responsáveis finais sobre quais trabalhos serão publicados e, para outras duas, a comissão editorial também participa desta etapa. Um editor considerou: "Informação privilegiada e não disponível para divulgação.” (Ed1). Percebe-se, nesse procedimento, aspectos revisados nos trabalhos de Weller (1995) e Hames (2007) que os avaliadores apenas aconselham ou sugerem o editor sobre a publicação ou não de um trabalho, ficando a tomada de decisão somente a cargo dos editores, em algumas revistas, e em outras também nas mãos de uma comissão editorial.

Os autores foram questionados a respeito da ocorrência de diferenças entre os procedimentos indicados nas revistas e os que foram realizados na revisão de seu artigo. Entre os respondentes, 59 $(85,6 \%)$ afirmaram não terem ocorrido diferenças; cinco $(7,2 \%)$ ocorreram diferenças e outros cinco $(7,2 \%)$ não tinham certeza. Os comentários seguintes evidenciam o exposto: "Ao ler os procedimentos, tem-se a impressão que o processo não é tão lento quanto foi. Entre eu mandar o artigo e ocorrer a publicação passaram-se 14 meses... O aceite foi dado no nono/décimo mês." (Au12) e "Em mais de uma vez foi absolutamente claro que os artigos não foram lidos com cuidado. Tive a nítida impressão que os pareceristas leram "a toque de caixa" para cumprir o prazo de revisão." (Au47). As demais respostas referiram-se à falta de comunicação, ao longo tempo de permanência na lista de espera para publicação ou às exigências de um avaliador quanto ao uso de normas técnicas. Esses casos de descontentamento são mínimos, demonstrando que as revistas estudadas seguem, geralmente, os procedimentos expressos nos fascículos.

Todas as etapas do processo de avaliação são executadas eletronicamente em cinco revistas, conforme responderam os editores. Apenas um periódico possui parte das etapas eletrônicas (recebimento dos trabalhos e publicação das edições). Esses dados revelam que as tecnologias de informação e comunicação foram adotadas pelas revistas analisadas para a sua produção, demonstrando preocupação com uma divulgação mais rápida do conhecimento gerado pelos cientistas, além de facilitar a administração das mesmas.

Quando indagados sobre casos de plágio, fabricação de resultados, falsificação ou submissão dupla de artigos, nos últimos anos da revista, apenas um editor indicou que não ocorreram, enquanto outro preferiu responder: "Informação privilegiada e não disponível para divulgação." (Ed1). Assim, entre quatro revistas ocorreram alguns casos relacionados ao plágio, submissão dupla de artigos e trabalho anteriormente publicado em periódico estrangeiro. A má conduta de pesquisadores está presente em todas as áreas do conhecimento e não é surpresa encontrá-la entre a comunidade de 
Ciência da Informação. O aspecto positivo é que tais casos foram identificados pelas revistas impedindo a publicação dos trabalhos.

Com relação aos conflitos de interesse entre os participantes do processo de avaliação, os editores assim se manifestaram: três editores indicaram a ocorrência de discordância quanto à avaliação, dois apontaram não ter ocorrido, enquanto outro indicou: "Informação privilegiada e não disponível para divulgação." (Ed1).

Os membros das comissões editoriais também foram questionados sobre esse tema. Entre os respondentes, dez indicaram que não tiveram conflitos e três afirmaram ter havido conflito. Entre aqueles que apontaram algum caso, o primeiro relatou discussões relacionadas ao fechamento de edições, o segundo indicou o fato de um artigo conter elementos que identificavam os seus autores impossibilitando a avaliação, e o terceiro entrou em conflito com o editor sobre a inclusão de determinados tipos de artigos na revista.

Quanto aos avaliadores, 93 (95,9\%) não apontaram a ocorrência de conflitos com editores, membros das comissões editoriais ou autores. Apenas três $(3,1 \%)$ indicaram algum tipo de conflito: o primeiro apontou conflitos éticos com o editor devido às falhas ocorridas durante o processo de avaliação que acabou por revelar o nome do parecerista ao autor do artigo; o segundo também relatou erros na condução dos procedimentos de avaliação; e o terceiro indicou conflitos ocasionados pela falta de concordância dos autores com o seu parecer. Apenas um avaliador (1\%) não respondeu à questão.

Assim como todos os outros respondentes, a maioria dos autores declarou não terem ocorrido conflitos (62 ou equivalente a 89,9\%). Cinco (7,2\%) indicaram algum conflito, sendo que quatro referiram-se à mesma revista. Os conflitos ocorreram entre os pareceristas e estavam relacionados com os comentários e/ou correções exigidas. Dois autores $(2,9 \%)$ preferiram não responder a essa questão. Pelos resultados obtidos, pode-se perceber que os conflitos de interesse ocorreram com uma minoria dos respondentes desta pesquisa.

Por fim, sobre as tendências da peer review em revistas científicas, nenhum dos editores opinou a favor de sua extinção. "Penso que se manterá como uma etapa indiscutivelmente importante da validação e legitimação do conhecimento científico." (Ed3), respondeu um deles. Para outro editor a revisão por pares

[. . .] continuará acontecendo, pois dá credibilidade ao artigo publicado e à revista que utiliza esse método de avaliação, considerando o reconhecimento e a notoriedade de seus avaliadores. Contudo, acreditamos que as instruções aos avaliadores serão cada vez mais 
exigentes no cumprimento dos prazos, na avaliação do texto e na escritura do parecer. (Ed4).

O pagamento para os avaliadores foi lembrado por outros dois editores: "Creio que os pares devam ser cadastrados num sistema único e remunerados por alguma entidade.” (Ed2) e

É uma atividade acadêmica que requer tempo para a sua execução. Os especialistas nem sempre encontram tempo para se dedicarem a essa tarefa, além de não serem remunerados financeiramente e sim, pagamento simbólico - prestígio, reconhecimento. (Ed6).

Da mesma forma que os editores, a maioria dos respondentes em cada uma das outras três categorias de sujeitos apontou para a continuação da avaliação pelos pares, sendo que alguns também indicaram possíveis alterações. A seguir, destaca-se algumas percepções: O processo deve "[...] ser mantido e ficar cada vez mais rigoroso, buscando uma objetividade maior, dado ao grau de complexidade crescente das diversas áreas do conhecimento." (Co9); "Vai seguir padrões abertos, ampliando o corpo de pareceristas." (Co13); "Ainda não foi inventado um processo que substitua a avaliação pelos pares com vantagens. Até que isto aconteça, ela deve sobreviver.” (Av34); “Acho que o sistema poderia ser aperfeiçoado, com uma escolha mais apurada dos pareceristas e da adequação de suas especialidade/linhas de trabalho e pesquisa à natureza dos artigos avaliados." (Av91); "Desde logo, parece-me necessário que se ganhe mais agilidade em todo o processo." (Au26) e "Sem avaliação pelos pares os artigos perderiam o caráter de científicos e, assim, independente do formato da revista, torna-se necessário manter essa forma de avaliação." (Au41). A manutenção do julgamento pelos pares em revistas científicas é, portanto, apoiada pela grande parte dos respondentes. Variadas propostas para sua melhoria foram destacadas, como por exemplo: pagamento aos consultores, mais rigor e exigência quanto à redação dos pareceres e ao cumprimento dos prazos pelos avaliadores, mais cuidado na seleção dos avaliadores, atualização dos critérios de revisão de originais, avaliação do trabalho desempenhado pelos consultores, emprego de recursos tecnológicos, revisão dos trabalhos pelo leitor, entre outros. Ainda, ressalta-se que a necessidade de tornar o julgamento mais rápido, diminuindo o tempo entre a submissão e a decisão final pela recusa ou aceitação dos trabalhos, foi citada por todas as categorias de sujeitos.

\section{CONSIDERAÇÕES FINAIS}


Através desta pesquisa, buscou-se retratar os principais procedimentos adotados para a revisão dos originais pelas revistas brasileiras em Ciência da Informação que obtiveram conceito A no Qualis, em 2006. Contudo, é preciso salientar que o pequeno número de periódicos estudados não permite fazer generalizações para todos os títulos da área, tampouco indicar quais os mais ou menos adequados. Considerou-se oportuno apresentar todas as percepções dos diferentes tipos de sujeitos (editores, membros das comissões editoriais, avaliadores, autores) para ressaltar as diferenças de sentimentos, mesmo quando eles fossem percebidos por poucos sujeitos. Acredita-se que a adoção deste procedimento enriqueceu o trabalho e mostrou a subjetividade dos atores que concorrem para a produção da ciência. Outra contribuição que o trabalho poderá trazer é a adoção, pelos editores, de novos procedimentos para a avaliação de originais mais aceitos pela comunidade científica. Às vezes, a mudança de algum detalhe poderá tornar o processo mais transparente, tornando a revista mais confiável aos pesquisadores da área.

Foi possível verificar que as revistas analisadas, em sua maioria, adotam procedimentos similares, como por exemplo: uso de critérios científicos de avaliação quanto à forma e conteúdo dos originais; realização de uma pré-avaliação dos artigos antes do seu encaminhamento para os pareceristas; emprego de critérios comuns para a seleção de avaliadores; verificação com os avaliadores sobre a sua disponibilidade de tempo para revisão de originais, entre outros. As diferenças principais referem-se ao formato do parecer solicitado aos avaliadores e à decisão final sobre a publicação dos artigos. Entretanto, tais diferenças não interferem significativamente no processo. Nota-se que tais procedimentos estão de acordo com os padrões comumente aceitos e reconhecidos pela ciência, conforme observado na literatura.

Pelas limitações apresentadas em relação, principalmente, à escolha dos periódicos (somente revistas com Qualis A Nacional), o estudo não se esgota aqui. Novas investigações poderão complementar este estudo, incluindo questões não verificadas ou, ainda, investigar outros periódicos do campo da Ciência da Informação, brasileiros ou estrangeiros, que recebam avaliações diferenciadas pela CAPES.

\section{REFERÊNCIAS}


ASSOCIATION OF LEARNED AND PROFESSIONAL SOCIETY PUBLISHERS; EUROPEAN ASSOCIATION OF SCIENCE EDITORS. Current Practices in Peer Review: results of a survey conducted during Oct/Nov 2000. [2000]. Disponível em:

$<$ http://www.alpsp.org/ngen public/article.asp? $\mathrm{id}=200 \& \mathrm{did}=47 \&$ aid=354\&st=\&oaid=-1 $>$. Acesso em: 23 out. 2007.

CAMPANARIO, J. M. El sistema de revisión por expertos (peer review): muchos problemas y pocas soluciones. Revista Española de Documentación Científica, Madrid, v. 25, n. 3, p. 267 285, 2002. Disponível em: $<$ http://redc.revistas.csic.es/index.php/redc/article/viewFile/107/171>. Acesso em: 20 abr. 2006.

CASTRO, R. C. F.; NEGRÃO, M. B.; ZAHER, C. R. Procedimentos Editoriais na Avaliação de Artigos para Publicação em Periódicos de Ciência da Saúde da América Latina e Caribe. Ciência da Informação, Brasília, v. 25, n. 3, p. 352-356, set./dez. 1996.

COSTA, S. M. de S. Mudanças no Processo de Comunicação Científica: o impacto do uso de novas tecnologias. In: MUELLER, S. P. M.; PASSOS, E. J. L. (Orgs.). Comunicação Científica. Brasília: UnB, 2000. p. 85-105.

DAVYT GARCÍA, A. Avaliação por Pares e o Processo Decisório nas Agências de Fomento à Pesquisa. O CNPq e a FAPESP. 2001. xiv, $214 \mathrm{f}$. Tese (Doutorado em Política Científica e Tecnológica) - Universidade Estadual de Campinas, Campinas, 2001. Disponível em: $<$ http://libdigi.unicamp.br/document/?code=vtls000236027>. Acesso em: 16 dez. 2007.

DAVYT GARCÍA, A.; VELHO, L. A Avaliação da Ciência e a Revisão por Pares: passado e presente. Como será o Futuro? História, Ciência, Saúde - Manguinhos, Rio de Janeiro, v. 7, n. 1, p. 93-116, mar./jun. 2000. Disponível em:

$<$ http://www.scielo.br/scielo.php?script $=$ sci arttext\&pid $=\mathrm{S} 0104-$ 59702000000200005\&lng=pt\&nrm=iso\&tlng=pt>. Acesso em: 10 jan. 2007.

GÉRVAS, J.; PÉREZ FERNÁNDEZ, M. La revisión por pares em las revistas científicas. Atención Primaria, Barcelona, v. 27, n. 6, p. 432-439, abr. 2001.

GLOGOFF, S. Reviewing the Gatekeepers: a survey of referees of library journals. Journal of the American Society for Information Science, Washington, v. 39, n. 6, p. 400-407, Nov. 1988.

HAMES, I. Peer Review and Manuscript Management in Scientific Journals: guidelines for good practice. Oxford: Blackwell, 2007.

KRONICK, D. A. Peer Review in 18th-century Scientific Journalism. JAMA: The Journal of the American Medical Association, Chicago, v. 263, n. 10, p. 1321-1322, Mar. 1990.

MCNUTT, R. A. et al. The Effects of Blinding on the Quality of Peer Review. JAMA: The Journal of the American Medical Association, Chicago, v. 263, n. 10, p. 1371-1376, Mar. 1990.

MEADOWS, A. J. A Comunicação Científica. Brasília, DF: Briquet de Lemos/Livros, 1999. 
MUELLER, S. P. M. A Seleção de Artigos Científicos para Publicação em Revistas Brasileiras: um levantamento de práticas e procedimentos adotados pelas revistas científicas brasileiras financiadas pelo CNPq e FINEP 1995-1996. Revista de Biblioteconomia de Brasília, Brasília, DF, v. 21, n. 2, p. 229-250, jul./dez. 1997.

STUMPF, I. R. C. Avaliação de Originais nas Revistas Científicas: uma trajetória em busca do acerto. In: FERREIRA, S. M.; TARGINO, M. G. (Orgs.) Preparação de Revistas Científicas: teoria e prática. São Paulo: Reichmann \& Autores, 2005.

. Avaliação pelos Pares nas Revistas de Comunicação: visão dos editores, autores e avaliadores. Perspectivas em Ciência da Informação, Belo Horizonte, v. 13, n. 1, p. 18-31, jan./abr. 2008. Disponível em:

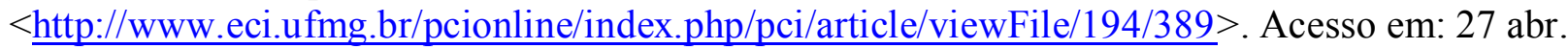
2008.

WELLER, A. C. Editorial Peer Review: research, current practices, and implications for librarians. Serials Review, Oxford, v. 21, n. 1, p.53-65, Spring 1995.

WILliamsON, A. What Will Happen to Peer Review? Learned Publishing, Hatfield, v. 16, n. 1, p. 15-20, Jan. 2003.

YANKAUER, A. Who Are the Peer Reviewers and How Much do they Review? JAMA: The Journal of the American Medical Association, Chicago, v. 263, n. 10, p. 1338-1340, Mar. 1990.

\begin{abstract}
The study examines the process of peer review used by the Brazilian journals of Information Science, wich were evaluated with A concept (national) according to Qualis/CAPES 2006, totaling six journals. The study subjects were the editors, members of editorial committees, reviewers and authors. Data collecting was conducted through questionnaires, specific to each category of subjects, and by the analysis of issues published in 2006. It presents the main peer review procedures adopted by the journals focused. It concludes that the journals, for the most part, follow similar procedures, in accordance with scientific standards.
\end{abstract}

Keywords: Peer review. Scientific journals. Information Science.

Originais recebidos em:03/02/2009

Aceito para publicação em:25/09/2009 